\title{
Research on Inspection, Quarantine and Supervision System of Horses Participating in Wuhan International Horse Race
}

\author{
Quan-an GUI \\ The School of Physical Education \\ Wuhan Business University \\ Wuhan, China \\ 542740013@qq.com
}

\author{
Zhong WU \\ The School of Physical Education \\ Wuhan Business University \\ Wuhan, China \\ 7849800@qq.com
}

\begin{abstract}
Combining the horse flu and horse herpes incidents in recent years and aiming at the current situation and problems of the inspection and quarantine work of the participating horses in Wuhan International Horse Race Festival, this paper mainly adopts the method of literature, logic analysis and other research methods to put forward more advanced and scientific horse inspection and quarantine technology in other countries, propose to improve the inspection and quarantine mechanism, optimize the pre-competition supervision system, and improve the supervision system of the participating horses in Wuhan International Horse Race Festival.
\end{abstract}

Keywords-Inspection; Quarantine; Supervision system; Wuhan International Horse Race

\section{INTRODUCTION}

In August 2007, there was a horse flu outbreak in Australia. The government announced that all horses in the country would be quarantined for three days and dozens of horse racing races would be cancelled on the 25 th. As a result, Australia's horse racing industry lost billions of dollars. In 2015, a horse flu incident broke out after the 13th Wuhan International Horse Racing Festival, which led to the cancellation of the following Chengdu International Horse Racing Festival. In early November 2016, a severe horse herpes virus broke out at the Los Angeles Equestrian Center. Approximately, 300 horses were quarantined and one of them was executed for serious illness in humanitarian way. This shows that horse flu has been a potential threat to horse racing around the world.

Before 1949, the horse racing style prevailed in Wu Han, which had three horse racing fields, namely Xishang, Huashang and Wanguo. When the race began, many wealthy businessmen from other places traveled thousands of miles to come to Wuhan at that time so that the reputation of "the capital of horse racing" spread everywhere. "Wuhan International Horse Racing Festival" is a large-scale city festival sponsored by Wuhan Municipal People's Government, whose aim is to create a splendid business card for Wuhan city. With "horse" as its theme, the competition is mainly guided by speed horse racing and equestrian events. Besides, national culture and horse culture complement each other well and sports, tourism and culture are also closely integrated. At the same time, high-level sports events and national arts are integrated. Wuhan will once again be established as the capital of modern horse racing in China. In 2003, Dongfang Macheng International Racetrack was completed and became the first international standard racetrack in the central part of China. In the same year, Wuhan held the first racetrack festival

Under this background, it is very essential to pay more attention to the epidemic prevention if we want to ensure the normal holding of Wuhan International Horse Racing Festival and the health of participating horses. However, as far as horse quarantine technology in our country is concerned, the inspection and quarantine of many kinds of viruses and its supervision system are not so perfect. So, how to do a good job in horse inspection and quarantine has become a top priority in horse racing.

\section{CURRENT SITUATION OF INSPECTION, QUARANTINE AND SUPERVISION OF HORSES PARTICIPATING IN WUHAN INTERNATIONAL HORSE RACING FESTIVAL}

After many years of holding, Wuhan International Horse Racing Festival has become a landmark event in Wuhan. In order to prevent the horses participating in the competition from infecting each other, the inspection and quarantine of the horses participating in the competition has always required strict, complicated and sensitive projects, and their "movement" is no less than receiving high-level diplomatic missions. The "passport" of horses participating in the Wuhan International Horse Racing Festival is much thicker than that of people. It is almost a detailed file and is accompanied by the health certificate of an authoritative organization. Apart from attaching importance to the inspection and quarantine of horses, the supervision of the successful holding of the competition is equally important. During the Dongfang Macheng Competition, the stables were set up according to the requirements of the competition. Six racing monitoring stables were set up in the racetrack according to the requirements to carry out overall monitoring of the horses before the competition. During the competition, Dongfang Macheng will conduct sampling tests and post-competition tests among participating horses. In the past 12 years, Wuhan has invested 2 billion yuan in horse racing infrastructure construction and built the most advanced 
supporting facilities in the world. Among them, the final control room system can accurately judge the result of the competition to 10,000 seconds. The opening time of the electric horse brake is accurate to milliseconds; More than 20 cameras are installed on the track to make the referee's judgment more just.

In terms of inspection and quarantine, the participating horses are the main players in the horse racing festival. In order to ensure the health of the horses, the law enforcement team stepped in ahead of schedule, strengthened the supervision of epidemic prevention and quarantine, and prevented the introduction of foreign epidemic diseases. Since August, the animal health supervision office of the East-west Lake District Agricultural Committee has been organized several times to work in Dongfang Macheng, Wuhan, to study and guide the epidemic prevention and quarantine work of the horses coming to China to ensure the health of the horses participating in the competition. One is to guide Dongfang Macheng to go to the starting place of horses many times to investigate the health status of the horses who signed up for the competition, and then to carry out immunization work against horse flu vaccine in the starting place of horses. The second is to urge Dongfang Macheng to repair and activate the quarantine field of Baiquan Domestication Base, to conduct quarantine observation on 410 horse races from foreign countries to China, to organize blood samples to test the titer of horse influenza immune antibody during the quarantine period, and to immunize horses with insufficient antibody titer and low protection rate from Dongfang Macheng in an emergency. The third is to carry out quarantine supervision in accordance with the law, send 10 official veterinarians to guide the scene, and check the animal quarantine certificate of the horses coming to China to participate in the competition in accordance with the law, and do a good job in various record ledgers such as clinical health examination. The fourth is to strengthen the disinfection of the entrances and exits outside the racecourse and the stables [1].

\section{INSPECTION, QUARANTINE AND SUPERVISION OF HORSES PARTICIPATING IN WUHAN INTERNATIONAL HORSE RACING FESTIVAL}

At present, the domestic horse escort mainly uses land transportation, while the main horse breeding area in our country is in Xinjiang Uygur Autonomous Region and transportation is not very convenient there, which makes the transportation distance of horses far away. At the same time, the altitude span is large, which will pose a threat to the health of horses. Horses are easily infected with virus fever during escort. Moreover, long-distance transportation will make them feel tired, which is more likely to cause low immunity and thus infect germs. In addition, we can notice that after the escort of the Hong Kong Jockey Club and other overseas competitions, horses will be quarantined for a period of time and their transport vehicles will be thoroughly disinfected. However, Wuhan International Horse Racing Festival ignores this point, which is easy to cause incompleteness of elimination of germs, thus laying hidden dangers for the health of participating horses.

In terms of supervision, daily epidemic prevention management and the use of inputs are the top priorities. During the competition, official veterinarians should be sent to carry out on-site management and overall supervision to strengthen the control of clinical health examination frequency, disinfection intensity and people flow and logistics. Dongfang Macheng still lacks supervision in this respect. After the competition, the whole process of horse pulling and horse loading should also be monitored to avoid other accidental injuries.

Take the Hong Kong Jockey Club as an example. As most of the horses participating in the competition are imported horses, the mode of transportation is mainly air transportation. Horses need to be strictly monitored and quarantined for three weeks before boarding the plane, and only relevant personnel can contact the horses within three weeks. After the horses arrived in Hong Kong, the horse's second epidemic prevention work was started before they got off the plane. All kinds of disinfectants are used inside and outside the trailer to disinfect thoroughly, even the tires are not bad. The horse will be sent to Hong Kong's local quarantine station for quarantine immediately after alighting from the plane [2].

In view of the above problems, there is still a lot of work to be done in the inspection, quarantine and supervision of the horses participating in the Wuhan Racetrack Festival. This paper will put forward some suggestions on the relevant work of Wuhan International Horse Racing Festival in combination with the inspection, quarantine and supervision work of other large horse racing events both in China and abroad.

\section{SUGGESTIONS FOR HORSE INSPECTION, QUARANTINE AND SUPERVISION WORK IN THE HORSE RACING FESTIVAL}

The problems of horse inspection and quarantine and supervision are not only present in modern times, the ancient people used their wisdom and at the same time left precious horse epidemic prevention experience for history. In ancient times, horses were regarded as indispensable "good companions" for people to ride and March. More than ten horse epidemics occurred during the southern song dynasty. Among these terrible diseases, cattle and horses were all infected and the losses were extremely heavy. The deaths of other animals, such as yeast, deer, wild boar, tiger and wolf, were countless. The government of the Southern Song dynasty also issued some policies on horse epidemic prevention. Firstly, it established a perfect veterinary inspection and quarantine system. The Southern Song dynasty followed the system of the Northern Song dynasty, stipulating that "anyone who enters a horse into an official would be taken by those who are not ill" and enumerating more than a dozen common diseases related to horses. The second is to improve the veterinary dispatch system and adjust the amount of "horse training". During the Southern Song dynasty, the government began to set up veterinarians in the "outline horse". In view of the increase in the fatality rate of horses, the government has made a large adjustment to the amount of "horses" bought by horse companies from different places to Hangzhou according to their distance [3].

This shows that horse epidemic prevention has been a big problem for people since ancient times. The problems in the inspection and quarantine and supervision of horses participating in the Wuhan International Horse Racing Festival 
mainly lie in the way in which horses are transported, which often reduces their physical quality and makes them vulnerable to the threat of germs, and the lack of quarantine work for horses entering or leaving the country. In terms of supervision, monitoring is not comprehensive enough, and transportation routes need to be carefully selected.

\section{A. The improvement of the Horse Inspection and Quarantine Mechanism in Wuhan International Horse Racing Festival}

(1) Establishing a quarantine system. Quarantine is an important measure to prevent the spread of animal diseases to Wuhan International Horse Racing Festival. The participating horses in Wuhan International Horse Racing Festival should join the air transportation. At the same time, the air transportation routes of participating horses should be carefully selected and the quarantine places should be determined based on this. The quarantine inspection period shall be set at $2-3$ weeks. During the quarantine period, the resident veterinarians shall enter the horse house for inspection several times a day to measure the body temperature of the horse race, carry out clinical quarantine on the health condition of the horse race, use clinical examination method, the clinical examination mainly focuses on sensory observation, observe whether the vital signs and activity performance of the animals are abnormal, and then judge whether there is animal plague or epidemic situation according to the knowledge of clinical veterinary medicine.

(2) Optimizing disinfection and epidemic prevention work and epidemic prevention measures. Three full-court sterilizations are required before entering the horse. Before the horse enters the arena, the entire oriental horse city should be subjected to three carpet sterilizations. The interval between each sterilizations is three days. It is necessary to control and disinfect the people and vehicles entering and leaving the stable core area. During the quarantine, the control of the people entering and leaving the stable core area is the first condition for successful quarantine. Disinfection pools should be set up at all intersections entering and leaving the stable core area and manned by special personnel. Irrelevant personnel are forbidden to enter. Besides, special vehicles to be transported to and from the ground are aseptically treated, and monitored "black boxes" are installed upon arrival at the station, which are tightly isolated, undergo detailed medical examinations or receive timely vaccination. All in all, the whole set of procedures must be meticulous.

(3) Harmless treatment of wastes. Regularly cleaning up and disinfecting horse sports grounds. To strengthen supervision and quarantine of forage grass to prevent epidemic diseases from being introduced into quarantine farms through forage grass. The horse excrement shall be sealed with plastic bags after cleaning and treated harmlessly. If abnormal horses need to be culled during quarantine, the dead bodies shall be treated harmlessly.

(4) Control of vectors. Carrying out regular weekly inspections of insect vectors and pest traps, monitoring the situation of insect vectors and pests in racecourses at any time, and controlling the spread of epidemic diseases. Cleaning up the stray animals around the isolation yard, assigning special personnel to catch stray dogs and cats, and putting in squirrel cages, rat poison, spray snake-proof sulfur powder, etc. to cut off the hidden danger of vector-borne organisms spreading epidemic diseases.

\section{B. The Optimization of the Pre-competition Supervision System for Participating Horses in Wuhan International Horse Racing Festival}

(1) Improving the daily epidemic prevention management. On the basis of legally requiring horse racing clubs to do a good job in the construction of hardware facilities for epidemic prevention, they should focus on guiding them to strengthen the management of basic epidemic prevention so as to ensure the implementation of various systems. Signs and barriers shall be set up at the border of major areas to control the flow of people and horses and prevent cross contamination.

(2) Doing a good job in horse archives management. Collecting photos of the front, right and left sides of the horse, and making a "horse individual file" to record the basic data and signs such as the horse number, horse name and age, so as to grasp the horse's movement situation in time.

(3) Standardizing veterinary records. Carrying out registration and filing management of veterinary personnel, regularly carrying out centralized laws, regulations and professional knowledge training to ensure that they learn, understand and abide by the law, and actively cooperating with epidemic prevention and quarantine work. A strong team of horse doctors is always ready to deal with the diseases and injuries of the horses during transportation and can hold remote discussions or consultations with experts through the internet [4].

\section{The Improvement of Supervision System During the Horse Race of Wuhan International Horse Race Festival}

During the competition, official veterinarians should be assigned to carry out on-site management and overall supervision to strengthen the work from the following four areas. Firstly, increasing the frequency of clinical health examination. Generally, it is not less than twice a day and it is added once within 2 hours before and after the competition. The contents mainly include the body temperature, heartbeat, breathing, visible mucous membrane color, skin, appetite and excrement and etc. The team veterinarians can be notified to take care of and observe the high body temperature and digestive dysfunction found during the examination in a timely manner. If necessary, they can take care of them separately in the isolation circle. The second is to intensify disinfection. In addition to routine disinfection of stables twice a week, the competition venue should be thoroughly disinfected before and after the competition. Also, it is necessary to supervise and guide the breeders, team veterinarians and transfer teachers to wipe and disinfect saddles and daily utensils before and after use, and to supervise the venue management to carry out harmless treatment of the excrement and waste produced in time to prevent mosquitoes and flies from breeding. Thirdly, strictly controlling the flow of people and logistics. Classifying and setting up area boundaries and channel signs, strictly registering and disinfecting vehicles and personnel entering and 
leaving the area, supervising the towing personnel to tow horses according to the prescribed routes and areas, and avoiding cross contamination; Fourthly, checking the surrounding environment. Conducting a thorough inspection of the area around the stadium to prevent dogs from entering, causing the risk of spread of the disease [5].

\section{SUMMARY}

To sum up, the influence of Wuhan International Horse Racing Festival has gradually increased, which has become more and more a national horse racing event and gained the attention of the world. The inspection, quarantine and supervision of the horses participating in the competition are complicated and meticulous, but there are inevitably shortcomings. Judging from the quarantine experience of domestic and international equestrian events, there is still a lack of quarantine, disinfection and epidemic prevention, routine supervision, competition supervision and other systems, which need to be optimized further.

Wuhan International Horse Racing Festival should be in line with international standards and have stricter requirements on quarantine and supervision of participating horses. The aim is to provide better quarantine services for future competitions, prevent the outbreak of the epidemic and push Wuhan International Horse Racing Festival to a higher stage in the near future.

\section{ACKNOWLEDGMENT}

This research was supported by the Humanities and Social Sciences Project of the Hubei Province Education Department "Research on Inspection, Quarantine and Supervision System of Horses Participating in Wuhan International Horse Race" (Grant No. 17G070).

\section{REFERENCES}

[1] Q.A. Gui, Z. Wu, and X.Q. Liu, "Study of Precautions of Escort and Quarantine of Horses for Wuhan International Horse Racing Festival:in Reference to Hong Kong Jockey Club," Journal of Wuhan Business University, vol. 30, pp. 23-25, June 2016.

[2] M.L. Tong, Y. Li, and Y. Jiang, "Comparison of Inspection and Quarantine Policies on Importing Racing Horses with Six Countries," Journal of Inspection and Quarantine, vol. 25, pp. 28-31, August 2015.

[3] K. Wang, S.F. Qiao, and W. Zhao, "Research on Safeguard Measures of the new pattern of "Internet + Inspection and quarantine," Information Technology and Informatization, vol. 27, pp. 80-81, August 2013.

[4] Z.X. Ma, Y.H. Wang, and Y.M. Jin, "Research on the Construction of Air-Cargo Inspection and Quarantine Information Platform System under the Background of Big-Data," Journal of Inspection and Quarantine, vol. 25, pp. 59-62, April 2015.

[5] Z.X. Ma, Y.H. Wang, and Y.M. Jin, "Research on the developments in Equine influenza vaccine," Chinese Journal of Preventive Veterinary Medicine, vol. 35, pp. 599-602, July 2013. 